\title{
Evaluation of Nicotiana Leaves Extract as Corrosion Inhibitor for Steel in Acidic and Neutral Chloride Solutions
}

\author{
D.E. Abd-El-Khalek, ${ }^{a,{ }^{*}}$ B.A. Abd-El-Nabey ${ }^{b}$ and A.M. Abdel-Gaber ${ }^{b}$ \\ ${ }^{a}$ Marine Chemistry Department, National Institute of Oceanography and Fisheries, \\ Elanfoshy, Alexandri, Egypt \\ ${ }^{b}$ Chemistry Department, Faculty of Science, Alexandria University, Ibrahimia, P.O. Box 426, \\ Alexandria 21321, Egypt
}

Received 27 February 2012; accepted 31 August 2012

\begin{abstract}
The inhibition of steel corrosion in hydrochloric acid and sodium chloride solutions by Nicotiana leaves extract was investigated by potentiodynamic polarization and electrochemical impedance spectroscopy measurements. Polarization curves showed that the extract behaves as a mixed type inhibitor in acidic medium, while it acts as anodic type in neutral medium. Impedance measurements indicated that the size of the semicircles obtained increased with increasing the concentration of the extract and decreasing the chloride ion concentration. Nicotiana leaves extract was found to be more effective in controlling corrosion of steel in acidic solution than in neutral one. The activation parameters of the corrosion reaction of steel in acid media in absence and presence of nicotiana leaves extract were also calculated and discussed.
\end{abstract}

Keywords: steel, corrosion, acid, neutral, extract.

\section{Introduction}

Inhibitors are generally used to reduce corrosion of metallic material in different media. Several chemical compounds have been investigated as corrosion inhibitors for mild steel in acid and neutral media [1-7]. The use of chemical inhibitors has been limited because of the environmental threat. Recently, due to environmental regulations, plant extracts have again become important because they are environmentally acceptable, readily available and a renewable source for a wide range of needed inhibitors. Plant extracts are viewed as an incredibly rich source of naturally synthesized chemical compounds that can be extracted by simple procedures with low cost. As new trend, several researchers used natural

\footnotetext{
"Corresponding author. E-mail: dalia1282002@yahoo.com
} 
products as corrosion inhibitors. Abdel-Gaber et al. [8] investigated the effect of extracts of some plants on the corrosion of steel in aqueous $1 \mathrm{M}$ sulphuric acid by electrochemical impedance spectroscopy (EIS) and potentiodynamic polarization techniques. Oguzie [9] studied also the corrosion inhibition of mild steel in $2 \mathrm{M}$ hydrochloric acid and $1 \mathrm{M}$ sulphuric acid by extracts of selected plants using a gasometric technique at temperatures of 30 and $60{ }^{\circ} \mathrm{C}$. The studied plant materials include leaf extracts of Occimum viridis, Telferia occidentalis, Azadirachta indica and Hibiscus sabdariffa, as well as extracts from the seeds of Garcinia kola. The effect of lupine and damsissa extracts on the corrosion of steel in $0.5 \mathrm{M} \mathrm{Na}_{2} \mathrm{SO}_{4}$ solution free from and containing 0.01 or $0.1 \mathrm{M} \mathrm{NaCl}$ were examined by potentiodynamic and electrochemical impedance spectroscopy techniques [10]. Also, olive leaves extract was studied as scale and corrosion inhibitor for steel surface in brine solution [11]. Earlier et al. [12] showed that the actual inhibitors in the plant extracts are usually alkaloids and other organic nitrogen bases, as well as carbohydrates, proteins and their acid hydrolysis products.

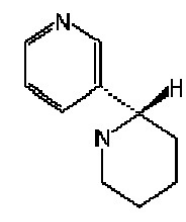

Anabasine

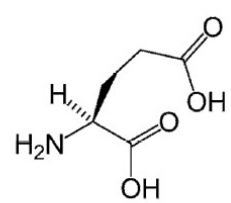

Glutamic acid

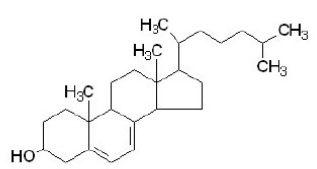

7-dehydrocholesterol

Figure 1. Chemical formulas of some chemical constituents of Nicotiana glauca leaves extract.

Nicotiana glauca is a much branched shrub or small tree often reaching 25 feet in nature. It is distributed in warm temperate, arid and subtropical, dry and moist regions, beside roadsides and along riverbanks. The plant is used for a variety of medicinal purposes and smoked by Native American groups. It is being investigated for use as a biofuel. The chemical constituents in Nicotiana glauca are shown in Fig. 1; anabasine is the principal alkaloid of Nicotiana glauca. It also contains many amino acids (glutamic acid and aspartic acid) and organic acids (malice acid)[13]. Additionally, another study indicates that 7dehydrocholesterol is found in Nicotiana glauca [14].

This work aims to investigate Nicotiana glauca extract as corrosion inhibitor of mild steel in acidic and neutral solutions.

\section{Experimental}

\section{Electrochemical tests}

Electrochemical impedance and polarization curve measurements were achieved using a Gill AC instrument. The frequency range for EIS measurements was 0.1 $\leq \mathrm{f} \leq 1 \times 10^{3} \mathrm{~Hz}$ with applied potential signal amplitude of $10 \mathrm{mV}$ around the rest potential. The data were obtained in a three-electrode mode; platinum sheet and saturated calomel electrodes were used as counter and reference electrodes respectively. The material used for constructing the working electrode was steel with the following chemical composition (wt.\%): C, 0.21; S, 0.04; Mn, 2.5; P, 
0.04; $\mathrm{Si}, 0.35$; balance Fe. The steel was encapsulated in epoxy resin in such a way that only one surface was left uncovered. The exposed area $\left(1 \mathrm{~cm}^{2}\right)$ was mechanically abraded with a series of emery papers of variable grades, starting with a coarse one and proceeding in steps to the finest (800) grade. The samples were then washed thoroughly with double distilled water, followed with A.R. ethanol and finally with distilled water, just before insertion in the cell. Before polarization and EIS measurements, the working electrode was introduced into the test solution and left for $10 \mathrm{~min}$ at the open circuit potential. Polarization curve measurements were obtained at a scan rate of $20 \mathrm{mV} / \mathrm{min}$ starting from cathodic potential $\left(\mathrm{E}_{\mathrm{corr}}-250 \mathrm{mV}\right)$ going to anodic direction. To test the reliability and reproducibility of the measurements, duplicate experiments were performed in each case at the same conditions.

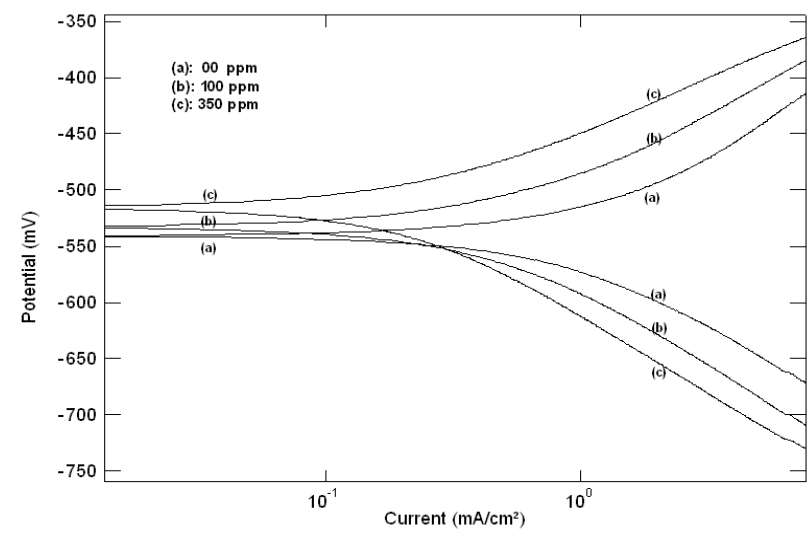

Figure 2. Potentiodynamic polarization curves for steel in $1 \mathrm{M} \mathrm{HCl}$ solution in absence and presence of different concentrations of Nicotiana leaves extract at $30^{\circ} \mathrm{C}$.

\section{Solutions preparation}

Double distilled water and analytical reagent-grade $\mathrm{NaCl}$ and $\mathrm{HCl}$ were used for preparing the solutions. Stock solution of the plant extracts was obtained by drying the plant for $1 \mathrm{~h}$ in an oven at $70{ }^{\circ} \mathrm{C}$ and grinding to powdery form. A $10 \mathrm{~g}$ sample of the powder was refluxed in $100 \mathrm{~mL}$ double distilled water for $1 \mathrm{~h}$. The refluxed solution was filtered to remove any contamination. The concentration of the stock solution was determining by evaporating $10 \mathrm{~mL}$ of the filtrate and weighing the residue.

\section{Results and discussion \\ Acidic solution}

Potentiodynamic polarization results

Typical potentiodynamic polarization curves for steel in 1 and $0.1 \mathrm{M} \mathrm{HCl}$ solutions in the absence and presence of different Nicotiana leaves extract concentrations are shown in Figs. 2 and 3, respectively. As seen, addition of Nicotiana leaves extract affects both anodic dissolution of steel and cathodic reduction reactions, indicating that the extract could be classified as a mixed-type inhibitor. The corrosion current density was calculated from the intersection of 
cathodic and anodic Tafel lines. The values of the electrochemical parameters for different plant extract concentrations are given in Table 1. The displayed data show that increasing plant extract concentration decreases the corrosion current density ( $\left.\mathrm{i}_{\text {corr }}\right)$ and shifts the corrosion potential (Ecorr) to more noble values. The percentage of inhibition efficiency $(\% \mathrm{P})$ was calculated from polarization measurements using the relation

$$
\% P=\left[\left(i_{o}-i\right) / i_{o}\right] \times 100
$$

where $i_{o}$ and $i$ are the corrosion current density in the absence and presence of plant extract, respectively. The slight variations in anodic and cathodic Tafel slopes ( $\beta \mathrm{a}$ and $\beta \mathrm{c}$ ) indicate that the inhibiting action is taking place by the simple blocking of the available cathodic and anodic sites on the metal surface.

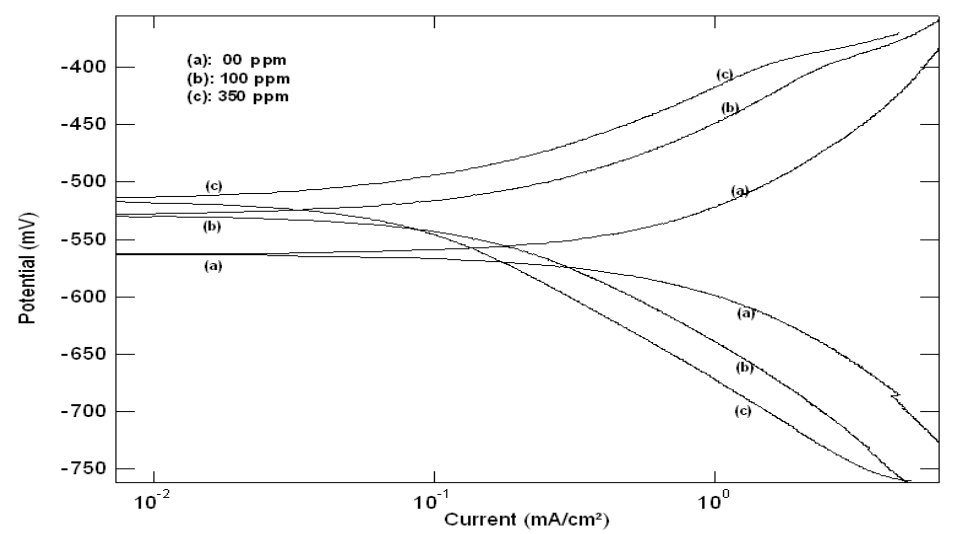

Figure 3. Potentiodynamic polarization curves for steel in $0.1 \mathrm{M} \mathrm{HCl}$ solution in absence and presence of different concentrations of Nicotiana leaves extract at $30^{\circ} \mathrm{C}$.

Table 1. Electrochemical polarization parameters of steel in 1 and $0.1 \mathrm{M} \mathrm{HCl}$ solutions in absence and presence of different concentrations of Nicotiana leaves extract at $30{ }^{\circ} \mathrm{C}$.

\begin{tabular}{|c|c|c|c|c|c|c|c|}
\hline \multirow{2}{*}{$\begin{array}{l}{[\mathrm{HCl}],} \\
\mathrm{mol} / \mathrm{L}\end{array}$} & \multirow{2}{*}{$\begin{array}{l}\text { Conc. } \\
\text { ppm }\end{array}$} & \multirow{2}{*}{$\begin{array}{c}-\mathbf{E}_{\text {corr. }} \\
\mathrm{mV}\end{array}$} & $\boldsymbol{\beta}_{\mathrm{a}}$ & $\boldsymbol{\beta}_{\mathrm{c}}$ & \multirow{2}{*}{$\begin{array}{c}\mathbf{i}_{\text {corr. }} \\
\mathbf{m A} / \mathbf{c m}^{2}\end{array}$} & \multirow{2}{*}{$\begin{array}{l}\text { Rate } \\
\text { mpy }\end{array}$} & \multirow{2}{*}{$\% \mathbf{P}$} \\
\hline & & & \multicolumn{2}{|c|}{ mV/ decade } & & & \\
\hline 1 & $\begin{array}{c}00 \\
100 \\
350\end{array}$ & $\begin{array}{l}547 \\
536 \\
517\end{array}$ & $\begin{array}{c}112 \\
93 \\
83\end{array}$ & $\begin{array}{l}107 \\
104 \\
113\end{array}$ & $\begin{array}{l}0.66 \\
0.29 \\
0.16\end{array}$ & $\begin{array}{l}7.69 \\
3.39 \\
1.82\end{array}$ & $\begin{array}{c}00 \\
60.6 \\
75.8\end{array}$ \\
\hline 0.1 & $\begin{array}{c}00 \\
100 \\
350\end{array}$ & $\begin{array}{l}555 \\
532 \\
518\end{array}$ & $\begin{array}{c}114 \\
94 \\
81\end{array}$ & $\begin{array}{l}124 \\
118 \\
128\end{array}$ & $\begin{array}{l}0.510 \\
0.135 \\
0.069\end{array}$ & $\begin{array}{l}5.95 \\
1.57 \\
0.81\end{array}$ & $\begin{array}{c}00 \\
73.5 \\
86.5\end{array}$ \\
\hline
\end{tabular}

The data displayed also that decreasing the concentration of $\mathrm{HCl}$ increases the inhibition action of the extract, which can be explained on the basis that increasing the concentration of chloride ion at the metal surface hinder the adsorption of extract species on the metal. 


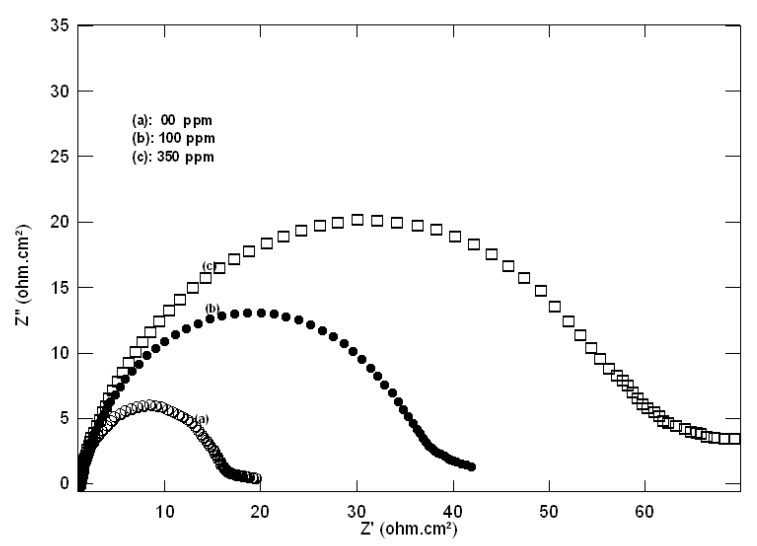

Figure 4. Nyquist plots for steel in $1.0 \mathrm{M} \mathrm{HCl}$ solution in the absence and presence of different concentrations of Nicotiana leaves extract at $30{ }^{\circ} \mathrm{C}$.

Electrochemical impedance spectroscopy results

The Nyquist plots for steel in 1.0 and $0.1 \mathrm{M} \mathrm{HCl}$ solutions in the absence and presence of different Nicotiana extract concentrations are shown in Fig 4 and 5. These plots indicate that the dissolution process occurs under activation control. The impedance response consisted of characteristic semicircles. These semicircles are of a capacitive type whose size increases with increasing Nicotiana leaves extract concentration.

The impedance spectra for different Nyquist plots were analyzed by fitting the experimental data to a simple equivalent circuit model (Fig. 6) which includes the solution resistance Rs and the double layer capacitance (Cdl), which is placed in parallel to charge transfer resistance element, Rct. The Rct value is a measure of electron transfer across the surface and it is inversely proportional to the corrosion rate.

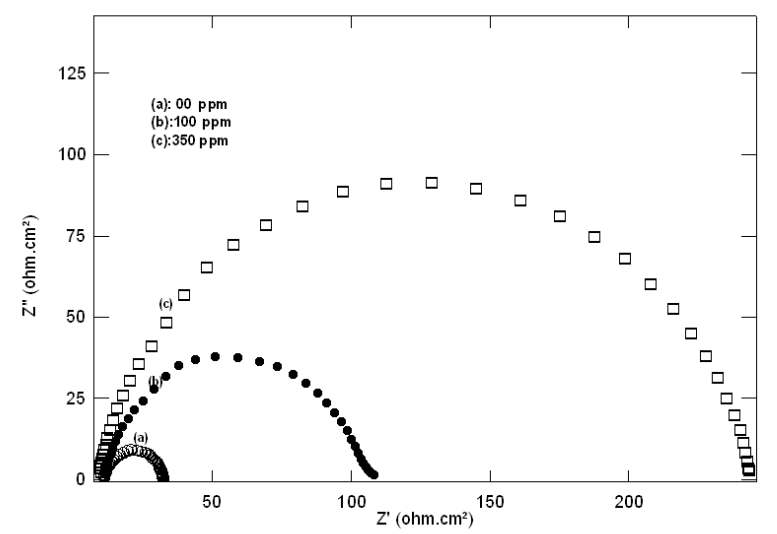

Figure 5. Nyquist plots for steel in $0.1 \mathrm{M} \mathrm{HCl}$ solution in the absence and presence of different concentrations of Nicotiana leaves extract at $30^{\circ} \mathrm{C}$.

The values of $\mathrm{R}_{\mathrm{ct}}$ and $\mathrm{C}_{\mathrm{dl}}$ for steel in 0.1 and $1 \mathrm{M} \mathrm{HCl}$ containing different Nicotiana leaves extract concentrations are shown in Table 2. The data indicate that the increasing of the charge transfer resistance is associated with a decrease in the double layer capacitance. The decrease in the $\mathrm{C}_{\mathrm{dl}}$ values could be attributed 
to the adsorption of the chemical constituents of Nicotiana leaves extract at the metal surface. It has been reported that the adsorption process on the metal surface is characterized by a decrease in $\mathrm{C}_{\mathrm{dl}}$ [15].

The $\% \mathrm{P}$ were calculated from impedance measurements using the relation

$$
\% \mathrm{P}=\left[\left(\mathrm{R}_{\mathrm{ct}}-\mathrm{R}_{\mathrm{cto}}\right) / \mathrm{R}_{\mathrm{ct}}\right] \times 100
$$

where $R_{\mathrm{ct} 0}$ and Rct are the charge transfer resistances in the absence and presence of the plant extract.

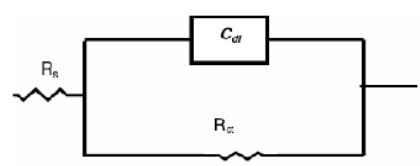

Figure 6. Equivalent circuit model.

Table 2. Computer fit results of the impedance spectra for steel electrode in $1 \mathrm{M}$ and $0.1 \mathrm{M} \mathrm{HCl}$ solutions in absence and presence of different concentrations of Nicotiana leaves extract at $30^{\circ} \mathrm{C}$.

\begin{tabular}{|l|c|c|c|c|c|}
\hline$[\mathrm{HCl}] /(\mathrm{mol} / \mathrm{L})$ & Conc. / ppm & $\mathrm{R}_{\mathrm{s}} /$ ohm.cm & $\mathrm{R}_{\mathrm{ct}} /$ ohm.cm & $\mathrm{Q}_{\mathrm{dl}} / \mu \mathrm{F}$ & $\% \mathrm{P}$ \\
\hline 1 & 0 & 1.23 & 15.6 & 468 & 0 \\
\hline & 100 & 0.95 & 37.8 & 451 & 60.0 \\
\hline 0.1 & 350 & 1.20 & 64.0 & 388 & 75.6 \\
\hline & 0 & 11.3 & 21.8 & 248 & 0 \\
\hline & 100 & 11.3 & 91.3 & 118 & 76.1 \\
\hline & 350 & 8.8 & 235 & 97 & 90.7 \\
\hline
\end{tabular}

The values of $\% \mathrm{P}$ are in quite good agreement with the results obtained previously from polarization measurements (Table 1).

\section{Activation parameters}

The effect of temperature on the corrosion rate of steel and inhibition efficiency of Nicotiana extract has been studied in $\mathrm{HCl}$ solutions. The activation parameters for the system were calculated from the Arrhenius-type plots and transition state equations. It has been pointed out by a number of authors [16-18] that the logarithm of the corrosion rate $(\mathrm{k})$ is a linear function with 1/T (Arrhenius equation):

$$
\ln \mathrm{k}=\ln \mathrm{A}-\mathrm{Ea} / \mathrm{RT}
$$

where Ea is the apparent effective activation energy, $\mathrm{T}$ the absolute temperature, $\mathrm{R}$ the universal gas constant and A the Arrhenius pre-exponential factor.

An alternative formulation of the Arrhenius equation is the transition state equation:

$$
\mathrm{k}=(\mathrm{RT} / \mathrm{Nh}) \exp \left(\Delta \mathrm{S}^{*} / \mathrm{R}\right) \exp \left(-\Delta \mathrm{H}^{*} / \mathrm{RT}\right)
$$

where $\mathrm{N}$ is the Avogadro's number, $\mathrm{h}$ the Plank's constant, $\Delta \mathrm{H}^{*}$ the enthalpy of activation and $\Delta \mathrm{S}^{*}$ is the entropy of activation. 


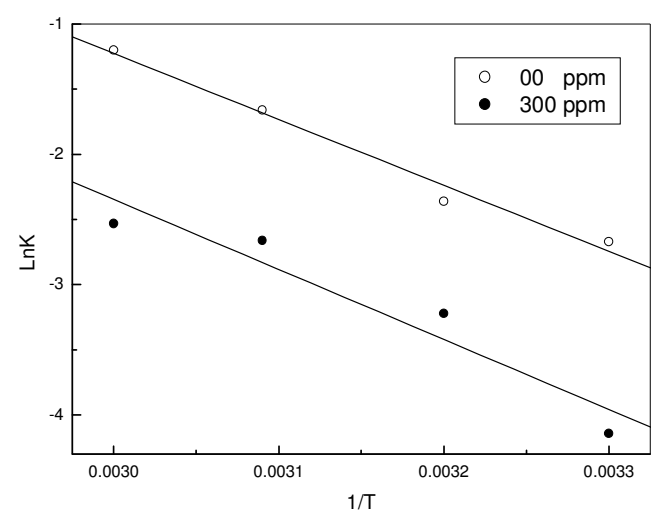

Figure 7. Linear least square plots of [ln k] vs. 1/T for steel corrosion in $1 \mathrm{M} \mathrm{HCl}$ in absence and presence of 300 ppm of Nicotiana leaves extract.

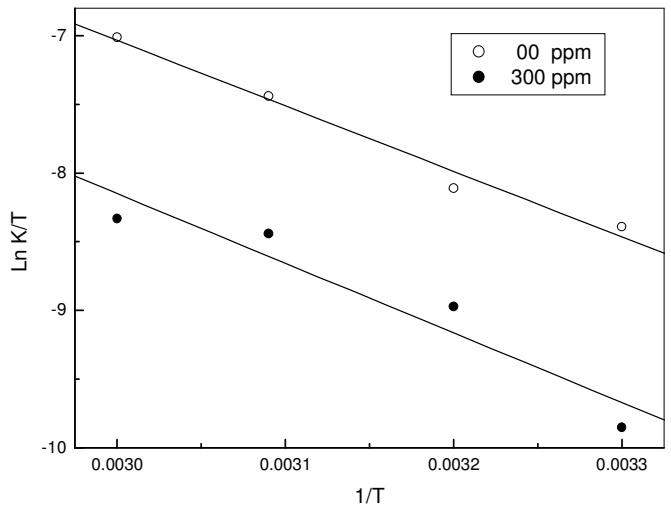

Figure 8. Linear least square plots of $[\ln \mathrm{k} / \mathrm{T}]$ vs. $1 / \mathrm{T}$ for steel corrosion in $1 \mathrm{M} \mathrm{HCl}$ in absence and presence of 300 ppm of Nicotiana leaves extract.

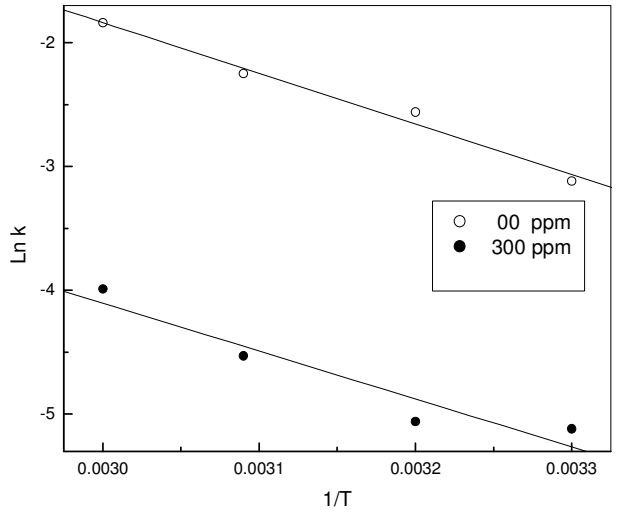

Figure 9. Linear least square plots of $[\mathrm{ln} \mathrm{k}]$ vs. $1 / \mathrm{T}$ for steel corrosion in $0.1 \mathrm{M} \mathrm{HCl}$ in absence and presence of 300 ppm of Nicotiana leaves extract. 


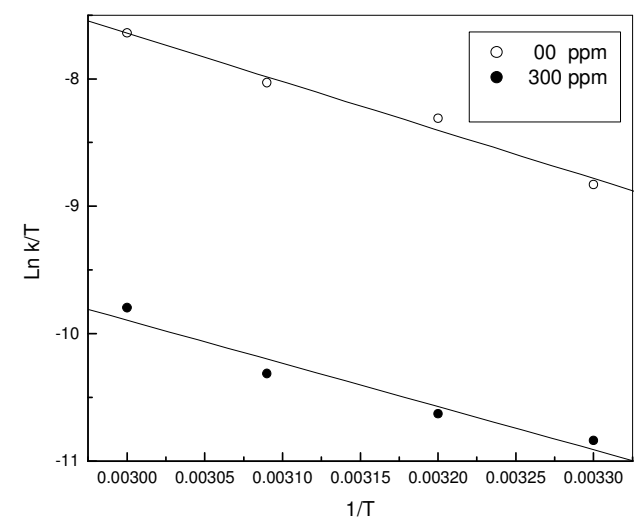

Figure 10. Linear least square plots of $[\ln \mathrm{k} / \mathrm{T}]$ vs. 1/T for steel corrosion in $0.1 \mathrm{M} \mathrm{HCl}$ in absence and presence of $300 \mathrm{ppm}$ of Nicotiana leaves extract.

Figs 7-10 give least square plots of [ln k] versus 1/T and [ln $(\mathrm{k} / \mathrm{T})]$ versus $1 / \mathrm{T}$ data for steel dissolution in 1.0 and $0.1 \mathrm{M} \mathrm{HCl}$ in the absence and in the presence of $300 \mathrm{ppm}$ of Nicotiana leaves extract, from which the values of the activation parameters Ea, $\Delta \mathrm{H}^{*}$ and $\Delta \mathrm{S}^{*}$ are calculated and produced in Table 3 . The higher values of Ea and $\Delta \mathrm{H}^{*}$ in presence of Nicotiana extract than those obtained for pure $1 \mathrm{M} \mathrm{HCl}$ indicated that, when the temperature was raised, a decrease in protection efficiency was obtained [18]. On the other hand, the slight decrease in their values in presence of the extract in $0.1 \mathrm{M} \mathrm{HCl}$ solution indicates that the effectiveness of this extract at higher temperature is not affected [19].The negative value of $\Delta \mathrm{S}^{*}$ implies that the activated complex represents an association rather than a dissociation step, meaning that a decrease in disordering takes place on going from reactants to the activated complex [20,21]. It is reported that the rate-determining step for the hydrogen evolution reaction on iron is the recombination of the adsorbed hydrogen atom to form $\mathrm{H}_{2}$ molecules [22-24].

Table 3. the thermodynamic parameters of activation concerning steel corrosion in 1 and $0.1 \mathrm{M} \mathrm{HCl}$ in absence and presence of $300 \mathrm{ppm}$ of Nicotiana leaves extract.

\begin{tabular}{|c|c|c|c|c|}
\hline \multirow{2}{*}[\mathbf{HCl}]{$/(\mathbf{m o l} / \mathbf{L})$} & \multirow{2}{*}{ Extract concentration } & \multicolumn{3}{|c|}{ Activation parameters } \\
\cline { 3 - 5 } & $\begin{array}{c}\mathrm{Ea} \\
(\mathrm{kJ} / \mathrm{mol})\end{array}$ & $\begin{array}{c}\Delta \mathrm{H}^{*} \\
(\mathrm{~kJ} / \mathrm{mol})\end{array}$ & $\begin{array}{c}\Delta \mathrm{S}^{*} \\
(\mathrm{~J} / \mathrm{mol} . \mathrm{K})\end{array}$ \\
\hline \multirow{2}{*}{1} & $00 \mathrm{ppm}$ & 41.17 & 38.76 & -134.09 \\
\cline { 2 - 5 } & $300 \mathrm{ppm}$ & 44.63 & 41.24 & -135.71 \\
\hline \multirow{2}{*}{0.1} & $00 \mathrm{ppm}$ & 33.29 & 30.93 & -162.51 \\
\cline { 2 - 5 } & $300 \mathrm{ppm}$ & 32.13 & 27.54 & -191.01 \\
\hline
\end{tabular}

Therefore, the transition state of the rate-determining recombination step represents a more orderly arrangement relative to the initial state, and, hence, a negative value of the entropy of activation is obtained in absence or presence of the extract. The value of $\Delta S^{*}$ is nearly the same in presence of the extract in 1 $\mathrm{M} \mathrm{HCl}$, while higher negative value of $\Delta \mathrm{S}^{*}$ is obtained in $0.1 \mathrm{M} \mathrm{HCl}$, which 
indicates that more ordered recombination step is obtained in presence of the extract molecules in low acid concentration rather than in high concentration.

\section{Neutral medium}

\section{Potentiodynamic polarization results}

Fig. 11 and 12 show the potentiodynamic polarization curves for steel in 0.1 and $1 \mathrm{M} \mathrm{NaCl}$ solutions in the absence and presence of different Nicotiana leaves extract concentrations. The figures clarify that the addition of the extract shifts the corrosion potential ( $\mathrm{E}_{\text {corr. }}$ ) into less negative values, indicating that this extract acts as an anodic type inhibitor. The values of the electrochemical parameters obtained from these curves are given in Table 4. The data clarify that the addition of plant extract decreases the corrosion current density (icorr) and shifts the corrosion potential (Ecorr) to less negative values, especially in $0.1 \mathrm{M} \mathrm{NaCl}$. The values of anodic and cathodic Tafel slopes ( $\beta \mathrm{a}$ and $\beta \mathrm{c}$ ) are slightly changed with the addition of Nicotiana extract, indicating that the inhibition process occurs without changing the mechanism [11]. As in acid medium, the inhibition efficiency of Nicotiana increases in $0.1 \mathrm{M}$ solution more than in $1 \mathrm{M}$ due to the effect of chloride ion concentration.

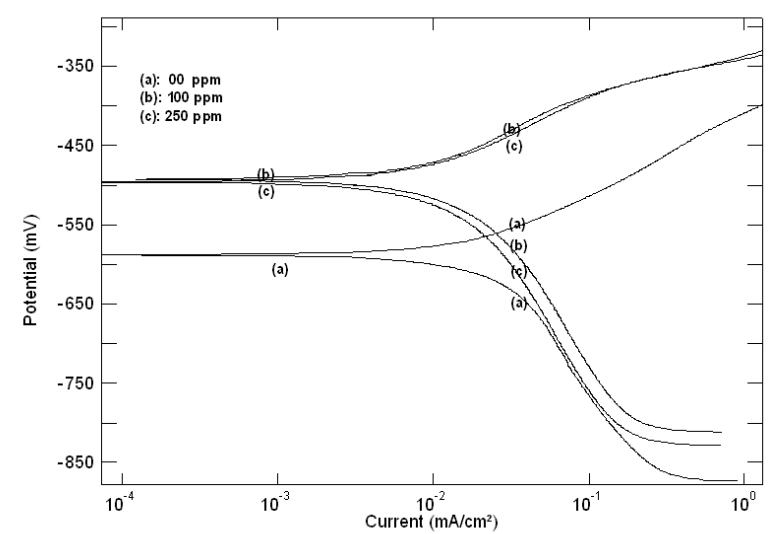

Figure 11. Potentiodynamic polarization curves for steel in $0.1 \mathrm{M} \mathrm{NaCl}$ solution in absence and presence of different concentrations of Nicotiana leaves extract at $30^{\circ} \mathrm{C}$.

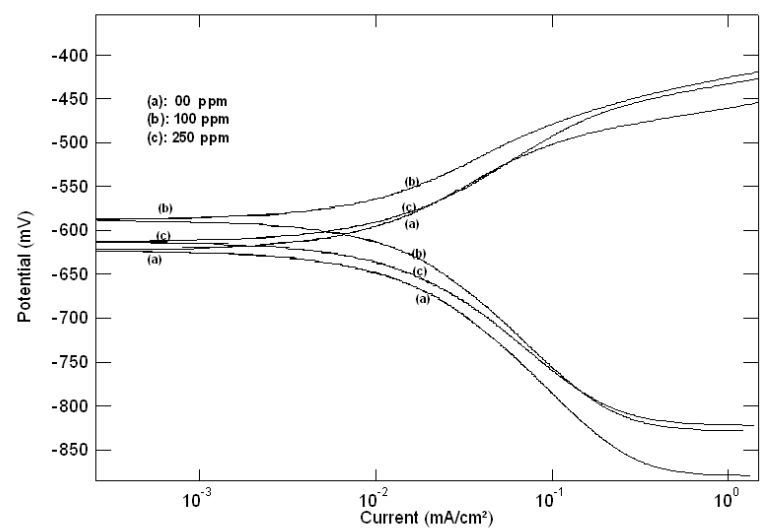

Figure 12. Potentiodynamic polarization curves for steel in $1.0 \mathrm{M} \mathrm{NaCl}$ solution in absence and presence of different concentrations of Nicotiana leaves extract at $30{ }^{\circ} \mathrm{C}$. 
Table 4. Electrochemical polarization parameters of steel in 1 and $0.1 \mathrm{M} \mathrm{NaCl}$ solution in absence and presence of different concentrations of Nicotiana leaves extract at $30{ }^{\circ} \mathrm{C}$.

\begin{tabular}{|c|c|c|c|c|c|c|}
\hline \multirow{2}{*}[\mathrm{NaCl}]{$/(\mathrm{Mol} / \mathrm{L})$} & \multirow{2}{*}{$\begin{array}{l}\text { Conc. } \\
\text { ppm }\end{array}$} & \multirow{2}{*}{$\begin{array}{c}-E_{\text {corr. }} \\
m V\end{array}$} & $\beta_{\mathrm{a}}$ & $\beta_{\mathrm{c}}$ & \multirow{2}{*}{$\begin{array}{c}\mathrm{i}_{\text {corr. }} \\
\mathrm{mA} / \mathrm{cm}^{2}\end{array}$} & \multirow{2}{*}{$\% \mathrm{P}$} \\
\hline & & & \multicolumn{2}{|c|}{$\mathrm{mV} /$ decade } & & \\
\hline \multirow{3}{*}{1} & 00 & 619 & 100 & 110 & 0.0070 & 00 \\
\hline & 100 & 583 & 85 & 121 & 0.0067 & 4.3 \\
\hline & 250 & 613 & 86 & 94 & 0.0065 & 7.1 \\
\hline \multirow{3}{*}{0.1} & 00 & 5835 & 83 & 137 & 0.014 & 00 \\
\hline & 100 & 494 & 95 & 127 & 0.0078 & 44.3 \\
\hline & 250 & 492 & 82 & 136 & 0.0063 & 55.0 \\
\hline
\end{tabular}

Electrochemical impedance spectroscopy results

Fig. 13 and 14 show Nyquist plots for steel in 0.1 and $1 \mathrm{M} \mathrm{NaCl}$ solution in the absence and presence of different Nicotiana leaves extract concentrations. The impedance response consisted of a distorted loop of a capacitive type whose size increases with increasing plant extract concentrations, which is indicative of increasing inhibitive efficiency of the extract with increasing its concentration.

The impedance spectra of different Nyquist plots were analyzed by fitting the experimental data to the equivalent circuit shown in Fig. 15, where CPE is the constant phase element which is defined by two values, $\mathrm{Q}$ and $n$. The impedance, $\mathrm{Z}$, of CPE is presented by

$$
\mathrm{Z}_{\mathrm{CPE}}=\mathrm{Q}^{-1}(\mathrm{i} \omega)^{-\mathrm{n}}
$$

where, $\mathrm{i}=(-1)^{1 / 2}, \omega$ is the frequency in $\operatorname{rad~s}^{-1}, \omega=2 \pi f$ and $f$ is the frequency in Hz. If $n$ equals one, then equation 1 is identical to that of a capacitor, $Z_{C}=(i \omega C)^{-1}$, where $\mathrm{C}$ is the ideal capacitance. For a non-homogeneous system, $n$ values range 0.9 -1. If $n$ equals 0.5 , a 45 degree line is produced on the complex-plane graph. A CPE with $n$ value of 0.5 can be used to produce a Warburg element. A Warburg element occurs when charge carrier diffuses through a material [25]. $Z$ dif is the diffusion impedance through the layer of products formed during immersion. Computer fit results of the impedance spectra obtained in absence and presence of different Nicotiana leaves extract concentrations are given in Table 5. The data show that the charge transfer resistance increases by increasing the concentration of the extract, which indicates that the extract acts as a corrosion inhibitor for steel in $0.1 \mathrm{M} \mathrm{NaCl}$ rather than in $1 \mathrm{M}$ solution. Moreover, increasing $\mathrm{R}_{\mathrm{f}}$ and $\mathrm{Rct}$ is accompanied by decreasing in the none ideal double layer capacitance values, $\mathrm{Q}_{\mathrm{dl}}$, suggesting that inhibition process takes place through adsorption of the chemical constituents of Nicotiana extracts on the metallic surface. 


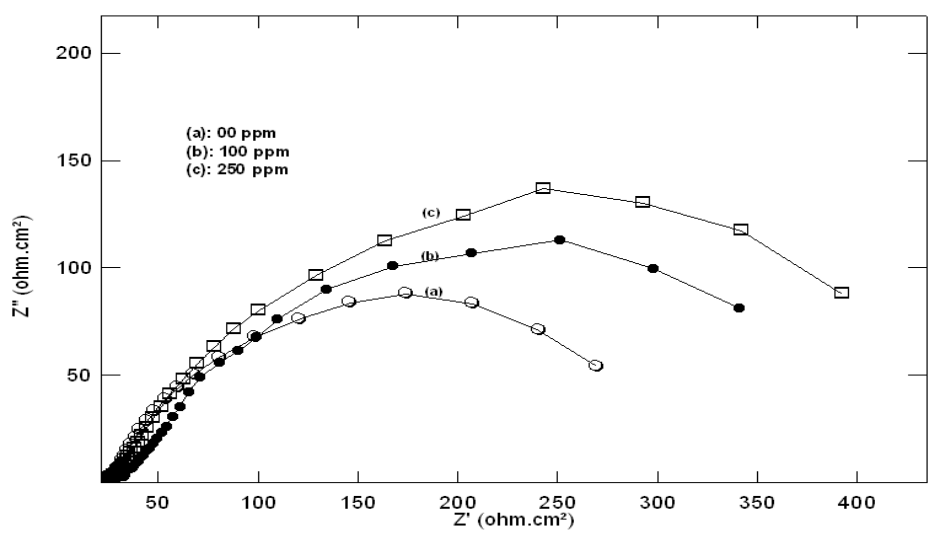

Figure 13. Nyquist plots for steel in $0.1 \mathrm{M} \mathrm{NaCl}$ solution in the absence and presence of different concentrations of Nicotiana leaves extract at $30{ }^{\circ} \mathrm{C}$.

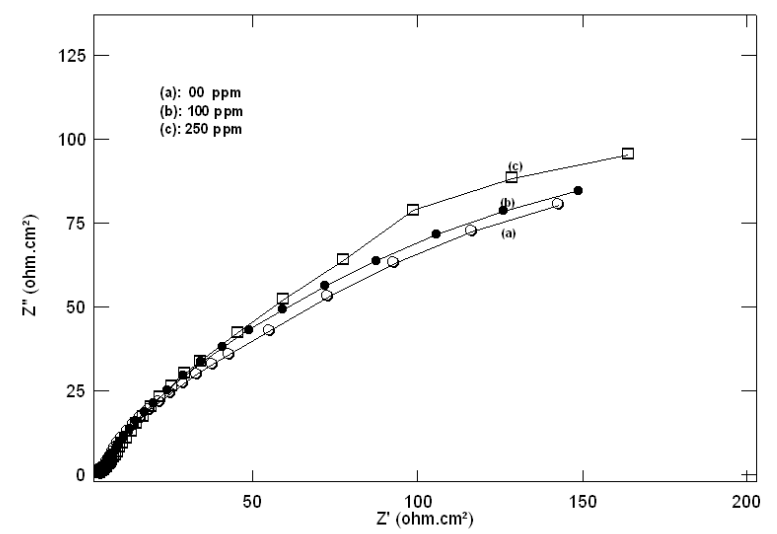

Figure 14. Nyquist plots for steel in $1 \mathrm{M} \mathrm{NaCl}$ solution in the absence and presence of different concentrations of Nicotiana leaves extract at $30{ }^{\circ} \mathrm{C}$.

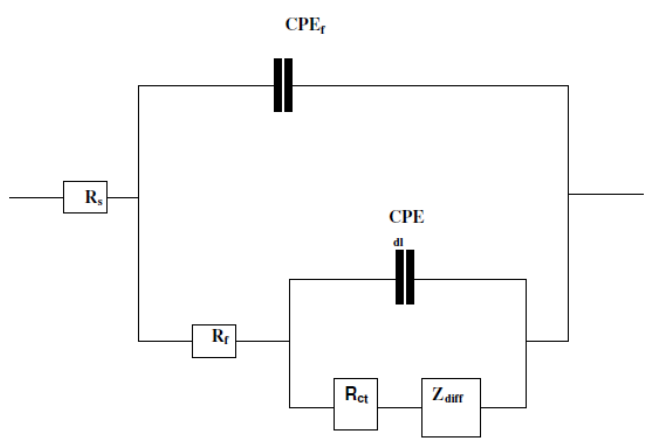

Figure 15. Schematic for the equivalent circuit model used to determine the impedance parameters for steel corrosion in 0.1 and $1 \mathrm{M} \mathrm{NaCl}$ solutions.

The polarization and impedance measurements indicated that the extract inhibits the corrosion processes by blocking the available cathodic and/or anodic sites of the metal surface through adsorption of the extract chemical constituents on the metal/solution interface. This phenomenon could take place via [26]: (i) electrostatic attraction between the positively charged protonated nitrogen atom and negatively charged mild steel surface (cathodic sites), (ii) dipole-type interaction between unshared electron pairs of oxygen atom or $\pi$ electrons- 
interaction with the vacant, low energy d-orbitals of Fe surface atoms (anodic sites), and (iii) a combination of all of the above (mixed type). The lower inhibition efficiency of Nicotiana extract in high chloride concentration solutions can be explained on the basis that increasing the concentration of chloride ion hinders the adsorption of extract molecules on the metal surface.

Table 5. Computer fit results of the impedance spectra for steel electrode in 1 and 0.1 $\mathrm{M} \mathrm{NaCl}$ solutions in the absence and presence of different concentrations of Nicotiana leaves extract.

\begin{tabular}{|l|c|c|c|c|c|c|c|c|c|}
\hline $\begin{array}{l}{[\mathrm{HCl}] /} \\
(\mathrm{mol} / \mathrm{L})\end{array}$ & Conc/ppm & $\mathrm{R}_{\mathrm{s}} /$ ohm.cm & $\mathrm{Q}_{\mathrm{f}} / \mu \mathrm{F}$ & $\mathrm{n}_{1}$ & $\begin{array}{c}\mathrm{R}_{\mathrm{f}} / \\
\mathrm{ohm} . \mathrm{cm}^{2}\end{array}$ & $\mathrm{Q}_{\mathrm{dl}} / \mu \mathrm{F}$ & $\mathrm{n}_{2}$ & $\begin{array}{c}\mathrm{R}_{\mathrm{ct}} / \\
\text { ohm.cm }\end{array}$ & $\% \mathrm{P}$ \\
\hline 1 & 0 & 5.3 & 1530 & 0.85 & 48.0 & 6374 & 0.63 & 259.6 & 0 \\
\hline & 100 & 4.5 & 1293 & 0.83 & 50 & 5252 & 0.58 & 273.6 & 5.1 \\
\hline & 250 & 5.0 & 3054 & 0.8 & 51.1 & 4739 & 0.49 & 344.9 & 24.7 \\
\hline 0.1 & 0 & 26.9 & 2172 & 0.6 & 0.36 & 899 & 0.82 & 296 & 0 \\
\hline & 100 & 30.6 & 1264 & 0.6 & 21.1 & 596 & 0.810 & 354 & 16.3 \\
\hline & 250 & 24.1 & 1882 & 0.57 & 24.4 & 413 & 0.834 & 470 & 37.0 \\
\hline
\end{tabular}

\section{Conclusions.}

The corrosion of mild steel in $\mathrm{HCl}$ and $\mathrm{NaCl}$ solutions is significantly reduced upon the addition of Nicotiana leaves extract. The inhibition efficiency increased with increasing the concentration of the extract and decreasing chloride ion concentration.

The results of potentiodynamic polarization measurements demonstrate that the Nicotiana leaves extract behaves as a mixed type inhibitor in acidic medium, while it acts as anodic type in neutral medium. The extract was found to be more effective in controlling corrosion of steel in acid solution than in neutral one.

At low acid concentration, protection efficiency of Nicotiana extract is not affected by raising the temperature and extract molecules increase the ordering of recombination step. On the other hand, in high acid concentration, the efficiency of the extract decreases with raising the temperature and the recombination step ordering is not affected.

\section{References}

1. Shukla SK, Quraishi MA. Corros Sci. 2010;52:314.

2. Aljourani J, Raeissi K, Golozar MA. Corros Sci. 2009;51:1836.

3. Achary G, Sachin HP, Naik YA, Venkatesha TV. Mater Chem Phys. 2008;107:44.

4. Saremi M, Dehghanian C, Mohammadi SM. Corros Sci. 2006;48:1404.

5. Wanga X, Yanga H, Wanga F. Corros Sci. 2011;53:113.

6. Mahdaviana M, Naderib R. Corros Sci. 2011;53:1194.

7. Obi-Egbedia NO, Obot IB. Corros Sci. 2011;53:263.

8. Abdel-Gaber AM, Abd-El-Nabey BA, Sidahmed IM, El-Zayady AM, Saadawy M. Corros Sci. 2006;48:2765.

9. Oguzie EE. Corros Sci. 2008;50:2992.

10. Abdel-Gaber AM, Abdel-Nabey BA, Saadawy M. Mater Corros. 2010;61:9999. 
11. Abdel-Gaber AM, Abdel-Nabey BA, Khamis E, Abd-El-Khalek DE. Desalination. 2011;278:337.

12. Barannik VP, Putilova IN. Uch Zap Mosk gosud Univ. 1945;78.

13. Tso TC, Burk LG, Sorokin TP, Engelhaupt ME. Plant Physiology. 1962;37:257.

14. Skliar M, Curino A, Milanesi L, Benassati S, Boland R. Plant Science. 2000;156:193.

15. Aramaki K, Hagiwara M, Nishihara H. Corros Sci. 1987;5:487.

16. Lyberatos G, Kobotiatis L. Corrosion. 1991;47:820.

17. Abd El-Rehim SS, Ibrahim MAM, Khaled KF. J Appl Electrochem. 1999;29:593.

18. Putilova IN, Balezin SA, Barannik VP. Metallic Corrosion Inhibitors. Oxford, UK: Pergamon Press; 1960.

19. Abdel-Gaber AM. Int J Appl Chem. 2007;3:231.

20. Abd-El-Nabey BA, Khamis E, Ramadan MSh, El-Gindy A. Corrosion. 1996;52:671.

21. Gomma MK, Wahdan MH. Mater Chem Phys. 1995;39:209.

22. Grigoryev VP, Eklik VU. Prot Met. 1968;4:517.

23. Grigoryev VP, Osipov OA. 3rd Europ Symp Corrosion Inhibitors; University of Ferrara, Italy. Ferrara; 1970. P. 473.

24. Antropov LI, Suvgira YA. Prot Met. 1967;3:597.

25. ZView2 help, Scribner Associates, 2000.

26. Schweinsgberg D, George G, Nishihara H. J Electrochem Soc. 1990;137:1354. 